\title{
Identifikasi Mikroplastik di Muara Sungai Kendal, Kabupaten Kendal
}

\author{
Kharisma Haidar Hanif, Jusup Suprijanto, Ibnu Pratikto \\ Departemen IImu Kelautan, Fakultas Perikanan dan Ilmu Kelautan, Universitas Diponegoro \\ J. Prof.H.Soedarto S.H, Tembalang, Semarang, Jawa Tengah 50275 Indonesia \\ ${ }^{*}$ Corresponding author, e-mail: khaeisma.haidar@gmail.com
}

\begin{abstract}
ABSTRAK: Kajian mengenai mikroplastik pada muara Sungai Kendal, Kabupaten Kendal, Jawa Tengah perlu dilakukan untuk mengetahui jenis polimer dan bentuk dari mikroplastik karena Sungai Kendal berpotensi membawa mikroplastik hingga ke laut. Penelitian mengenai mikroplastik ini terbagi dalam 3 tahap yaitu pengambilan, pengolahan, dan identifikasi. Pengambilan sampel pada permukaan laut menggunakan plankton net $60 \mu \mathrm{m}$ pada 4 stasiun berbeda. Pengolahan sampel dilakukan dengan 3 tahap yaitu pendegradasian bahan organik, pemisahan densitas, penyaringan. Identifikasi polimer mikroplastik menggunakan FTIR (Fourier Transform Infra Red) dan identifikasi bentuk menggunakan mikroskop stereo. Hasil identifikasi polimer mikroplastik yang terdapat pada muara Sungai Kendal adalah polyethylene dan polypropylene. Bentuk mikroplastik yang didapatkan adalah fragment, film, foam, dan fiber.
\end{abstract}

Kata kunci: Identifikasi; Mikroplastik; FTIR

\section{Identification of Microplastics at Kendal Estuary, Kendal Regency}

ABSTRACT: The study of microplastics in Kendal Estuary, Kendal Regency, Central Java, is necessary to know the polymer and shape of microplastics because Kendal River has potential to bring microplastics to ocean. This study contains three steps of processing. The first step is sampling, then sample processing, and identification. Sample of microplastics is taken in surface water using plankton net $60 \mu \mathrm{m}$ at 4 stations. Sample processing had three steps, first is the degradation of organics matter, density separation, then sample filtration. Polymer identification used FTIR (Fourier Transform Infrared) and shape identification used stereo microscope. The results of polymer identification indicate that is two type of polymer, that is polyethylene and polypropylene. the shape of microplastics is fragment, film, foam, and fiber

Keywords: Identification; Microplastic; FTIR

\section{PENDAHULUAN}

Sampah laut (marine debris) merupakan benda padat persistent, diproduksi oleh manusia, secara langsung atau tidak langsung, sengaja atau tidak sengaja, dibuang atau ditinggalkan di dalam lingkungan laut. Macam - macam sampah laut diantaranya adalah plastik, kain, busa, styrofoam, kaca, keramik, logam, kertas, karet, dan kayu (Lippiat et al., 2013). Potensi efek sampah laut secara kimia ikut meningkat seiring menurunnya ukuran dari partikel sampah, sedangkan efek secara fisik meningkat seiring meningkatnya ukuran makrodebris (UNEP, 2016).

Limbah plastik yang terdapat dilaut dan terpapar sinar ultraviolet serta terjadinya proses dekomposisi dapat mengalami perubahan ukuran. Ukuran tersebut dapat dibagi menjadi 4 tingkat, yaitu makroplastik (>25mm), mesoplastik $(5-25 \mathrm{~mm})$, mikroplastik $(5-1 \mu \mathrm{m})$ dan nanoplastik $(<1 \mu \mathrm{m})$ (Iwasaki et al., 2017). Mikroplastik yang terdapat di laut dapat berasal dari mikroplastik primer dan mikroplastik sekunder. Mikroplastik primer, yaitu plastik yang dibuat dalam ukuran mikroskopis, sedangkan mikroplastik sekunder merupakan mikroplastik yang terbentuk karena adanya proses degradasi dari plastik berukuran makro (Jiang et al., 2018).

Solomon dan Palanisami (2016) menjelaskan bahwa mikroplastik dan makroplastik dapat ditemukan dilaut dikarenakan 3 faktor, yaitu terbawa oleh angin, terbawa aliran sungai, dan adanya kegiatan manusia di laut ataupun di daerah pesisir. Sampah makroplastik yang terdapat di laut 
kemudian terdegradasi karena terpapar sinar ultra violet, terpengaruh oleh angin, gelombang dan arus laut, atau gigitan hewan yang menyebabkan makroplastik berubah ukurannya menjadi mikroplastik.

Mikroplastik yang telah tersebar pada ekosistem laut, termasuk di daerah seperti kutub akan mempengaruhi organisme laut yang terdapat pada ekosistem tersebut. Pengaruh tersebut antara lain adalah terganggunya penyerapan energi oleh biota, sekresi hormon, laju pertumbuhan, dan kapasitas reproduksi biota. Selain efek yang dapat ditimbulkan oleh mikroplastik terhadap biota, mikroplastik yang dikonsumsi oleh binatang, tidak hanya mempengaruhi biota yang memakannya, tetapi dapat mempengaruhi manusia bila manusia memakan biota yang telah terpapar mikroplastik. Berdasarkan hal tersebut, mikroplastik yang terakumulasi dilaut dapat membahayakan bagi biota laut begitu juga terhadap manusia (Jiang et al., 2017).

Pertambahan jumlah penduduk setiap tahunnya dan diiringgi dengan penggunaan plastik oleh manusia dalam kehidupan sehari - hari, dapat menyebabkan mikroplastik yang bermuara ke laut dapat selalu bertambah jumlahnya. Pertambahan volume sampah setiap tahunnya dapat terlihat pada tahun 2006, volume sampah di Kabupaten Kendal hanya 55,06 $\mathrm{m}^{3}$ per hari dan pada tahun 2009 meningkat menjadi $63 \mathrm{~m}^{3}$ per hari (Pemerintah Kabupaten Kendal, 2012). Peningkatan sampah plastik yang terjadi tersebut dikhawatirkan juga dapat mempengaruhi jumlah mikroplastik yang bermuara ke laut. Bertambahnya mikroplastik dilaut dikhawatirkan dapat masuk ke rantai makanan dan mempengaruhi biota didalamnya.

Sungai Kendal yang mengalir dari darat kelaut dengan panjang 9,5 km, luas DAS (Daerah Aliran Sungai) 40,56 km², dan debit air sungai sebesar $216 \mathrm{~m}^{3} / \mathrm{dtk}$ (Dinas Pusdataru, 2017) memiliki potensi untuk membawa sampah mikroplastik. Potensi tersebut dapat dicontohkan dengan dilaluinya Kecamatan Patukangan - Pegulon dan Desa Bandengan oleh Sungai Kendal. Kecamatan Patukagan - Pegulon merupakan salah satu kecamatan yang berada di pusat Kota Kendal dimana daerah tersebut merupakan kawasan industri dan padat penduduk (Rasyid et al., 2017). Desa Bandengan yang terletak di Kecamatan Kendal, memiliki kondisi lingkungan yang terlihat kumuh dan terpolusi seperti pembuangan sampah yang tidak pada tempatnya yaitu pada pinggir sungai sehingga memungkinkan terbawanya sampah plastik kelaut (Poedjiastoeti dan Mila, 2008). Maka dari itu, Sungai Kendal yang berpotensi membawa sampah mikroplastik membutuhkan adanya penelitian untuk mengkaji jenis bentuk dan polimer mikroplastik di muara Sungai Kendal.

\section{MATERI DAN METODE}

Materi yang diteliti adalah mikroplastik yang diambil dari muara Sungai Kendal, Kabupaten Kendal, Jawa Tengah, di 4 titik pengambilan berbeda (Tabel 1). Sampel pada permukaan air laut ditimba

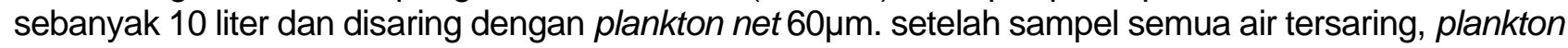
net dibilas dengan air sehingga seluruh sampel mikroplastik masuk kedalam core bervolume $750 \mathrm{ml}$ dan tidak tertinggal dijaringnya (Suhenda, 2008). Hasil penyaringan dimasukkan dalam botol sampel dan diawetkan dengan larutan ethanol 70\% 24,5ml (Viršek, 2016).

Pengolahan sampel mikroplastik dilakukan berdasarkan 3 tahap, yaitu pendegradasian bahan organik, pemisahan densitas, dan penyaringan. Sampel air laut diambil dengan volume $250 \mathrm{ml}$ kemudian dicampurkan dengan $\mathrm{H}_{2} \mathrm{O}_{2} 250 \mathrm{ml}$. Pencampuran tersebut digunakan agar bahan organik yang ikut tersaring dapat terdegradasi dan hanya tersisa bahan anorganik.(Lusher et al., 2017) (Wang et al., 2018).

Tabel 1. Koordinat Stasiun Pengambilan Sampel

\begin{tabular}{ccc}
\hline Stasiun & Bujur & Lintang \\
\hline ST.1 & $6^{\circ} 52^{\prime} 42^{\prime \prime}$ & $110^{\circ} 13^{\prime} 53^{\prime \prime}$ \\
ST.2 & $6^{\circ} 52^{\prime} 51^{\prime \prime}$ & $110^{\circ} 14^{\prime} 05^{\prime \prime}$ \\
ST.3 & $6^{\circ} 52^{\prime 2} 22^{\prime \prime}$ & $110^{\circ} 13^{\prime} 48^{\prime \prime}$ \\
ST.4 & $6^{\circ} 52^{\prime} 31^{\prime \prime}$ & $110^{\circ} 13^{\prime} 44^{\prime \prime}$ \\
\hline
\end{tabular}


Pemisahan densitas terhadap sampel dilakukan agar mikroplastik bermassa jenis tinggi dapat ikut terapung dipermukaan dan terpisah dari material lainnya. Pemisahan densitas ini dilakukan menggunakan $\mathrm{ZnCl}_{2} 800 \mathrm{gr}$. Pencampuran tersebut dimaksudkan untuk meningkatkan densitas sampel air laut menjadi $1,6 \mathrm{gr} / \mathrm{cm}^{3}$ (Wang et al., 2018).

Pemisahan sampel mikroplastik dilakukan dengan 2 kali penyaringan. Penyaringan pertama menggunakan mesh stainless stell $74 \mu \mathrm{m}$ (Ayuningtyas et al., 2019) kemudiam hasil penyaringan dimasukkan kedalam botol sampel dan digunakan dalam identifikasi jenis polimer mikroplastik. Penyaringan kedua dilakukan dengan kertas Whatman $36 \mu \mathrm{m}$ (Thiele et al., 2019) dan hasil penyaringan digunakan untuk identifikasi bentuk mikroplastik. Penyaringan dengan 2 tahap dilakukan agar sampel yang didapatkan dapat lebih bervariasi dan akurat.

Identifikasi mikroplastik dilakukan untuk mengetahui jenis bentuk mikroplastik dan jenis polimernya. Jenis bentuk mikroplastik dapat diamati menggunakan mikroskop stereo yang dihubungkan dengan Scope Image 9.0 sedangkan identifikasi jenis polimer mikroplastik dapat menggunakan FTIR (Fourier Transform Infrared).

\section{HASIL DAN PEMBAHASAN}

Identifikasi bentuk mikroplastik pada sampel air laut di muara Sungai Kendal menggunakan mikroskop stereo, didapatkan 4 macam bentuk mikroplastik yaitu fragment, fiber, film, dan foam (Gambar 1). Keempat bentuk tersebut dapat bersumber dari plastik berukuran makro yang terdegradasi hingga ukurannya berubah menjadi mikro. Bentuk dari fragment dan film dapat berasal dari plastik keras seperti kantong plastik, wadah plastik, atau mainan. Fiber dapat ditemukan dikarenakan terdapatnya kegiatan penangkapan ikan di daerah tersebut menggunakan arad yang memungkinkan serat dari alat tangkap tersebut ada yang terdegradasi saat pemakaiannya, sedangkan foam dapat berasal dari bahan pelapis kapal yang digunakan untuk kegiatan penangkapan ikan di daerah tersebut.

Bentuk mikroplastik yang didapatkan, dikategorikan kedalam 4 bentuk tersebut dikarenakan mikroplastik yang dikategorikan sebagai fiber dapat berasal dari darat seperti sisa-sisa pencucian pakaian atau dari alat tangkap ikan yang digunakan nelayan. Mikroplastik berbentuk film dapat berasal dari kegiatan manusia seperti penggunaan kantong plastik, pembungkus plastik, dan botol plastik yang tidak di daur ulang dengan baik. Fragment merupakan bentuk mikroplastik yang dapat berasal dari penggunaan barang dari plastik yang keras seperti peralatan rumah tangga. Pembeda antara bentuk fragment dan film adalah film terlihat trasparan sedangkan fragment tidak transparan. Sedangkan, mikroplastik berbentuk foam dapat berasal dari pelapis kapal dengan ciri memiliki struktur berongga (Yin et al., 2019).

Identifikasi jenis polimer mikroplastik pada 4 stasiun menggunakan FTIR yang disajikan pada Gambar 2. Hasil pengujian didapatkan bahwa terdapatnya beberapa puncak panjang gelombang yang menunjukkan ikatan suatu senyawa (Tabel 2). Berdasarkan pembacaan nilai puncak panjang gelombang, dapat diidentifikasi bahwa terdapatnya 3 jenis polimer mikroplastik yaitu polyethylene (PE), polypropylene (PP), dan polyamide. Pendugaan jenis polimer polyethylene dan polypropylene pada sampel ditandai dengan adanya puncak panjang gelombang pada rentang $2935-2915 \mathrm{~cm}^{-1}$ yang mengiterpretasikan adanya ikatan $\mathrm{CH}$ stretch. Ikatan $\mathrm{CH}$ dijadikan suatu pendugaan karena penyusun utama dari PE dan PP adalah $\mathrm{CH}$ (Syakti, 2017). Mikroplastik berjenis PE dapat berasal dari kantong plastik, bungkus deterjen, botol shampoo. Mikroplastik berjenis PP dapat berasal dari tutup botol, sedotan, dan mainan berbahan plasti (Pawar et al., 2016).

Pendugaan jenis polimer polyamide ditandai dengan adanya puncak panjang gelombang pada rentang $1650-1620 \mathrm{~cm}^{-1}$ yang menandakan terdapatnya ikatan $\mathrm{NH}$ primary amine (bending). Ikatan $\mathrm{NH}$ merupakan penyusun utama dari polyamide atau diketahui juga sebagai nylon (Maulina, 2016). Polyamide dapat berasal dari alat tangkap ikan yang digunakan nelayan setempat ataupun dari serat - serat kain yang hanyut ke laut (Pawar et al., 2016). 

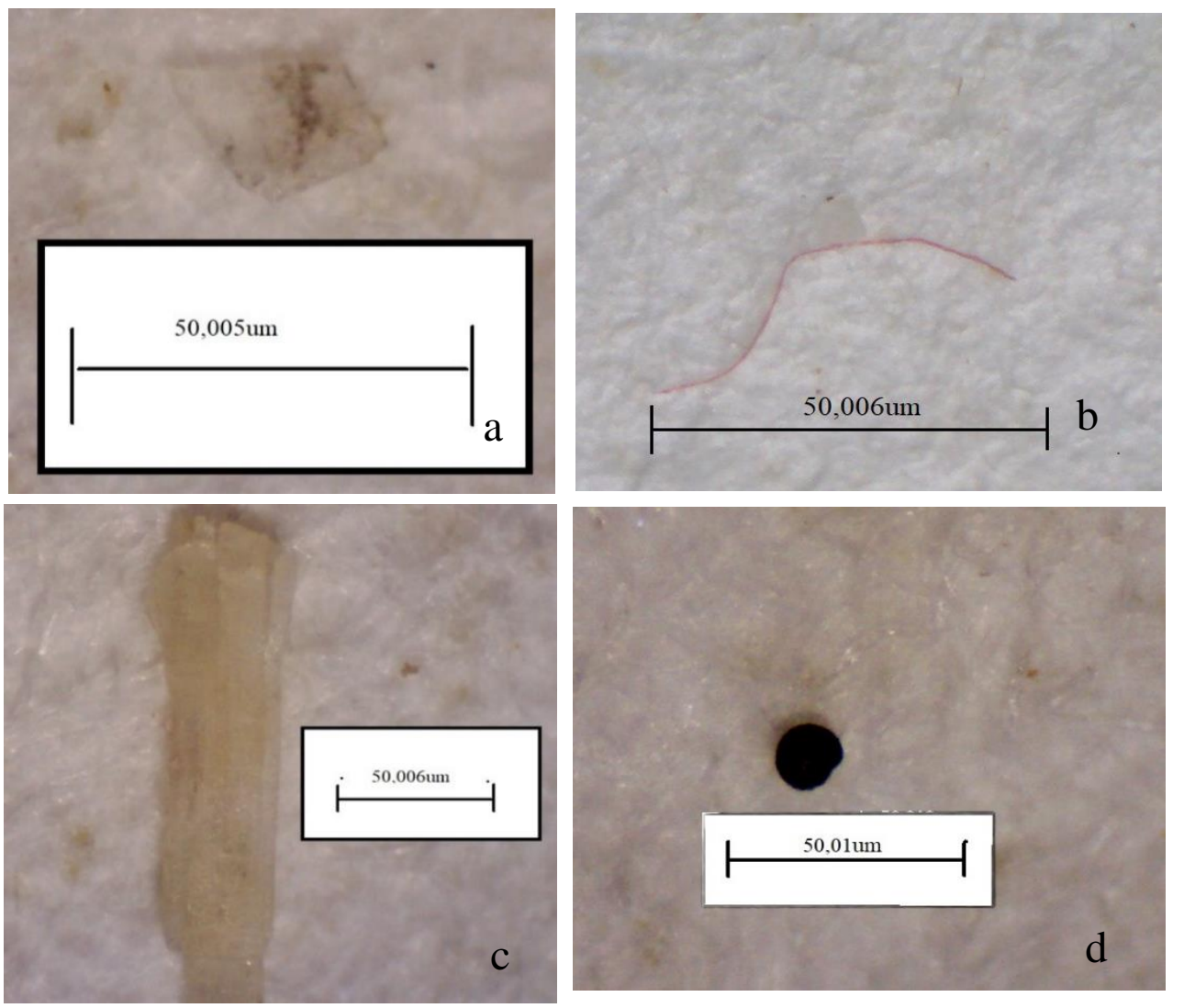

Gambar 1. Bentuk Mikroplastik pada Muara Sungai Kendal, Kabupaten Kendal : a.Film; b. Fiber. c. Fragmen; d. Foam

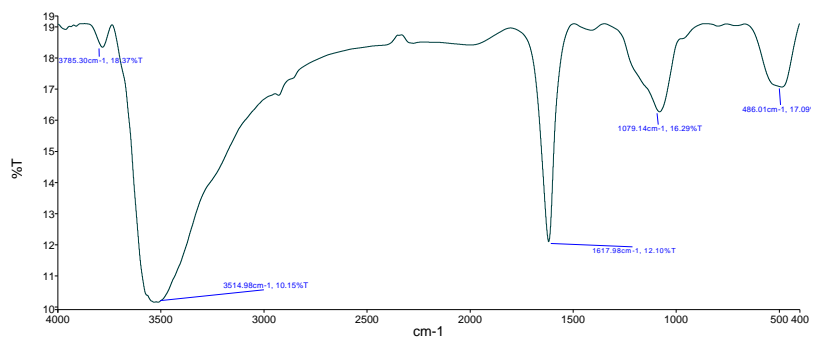

(a)

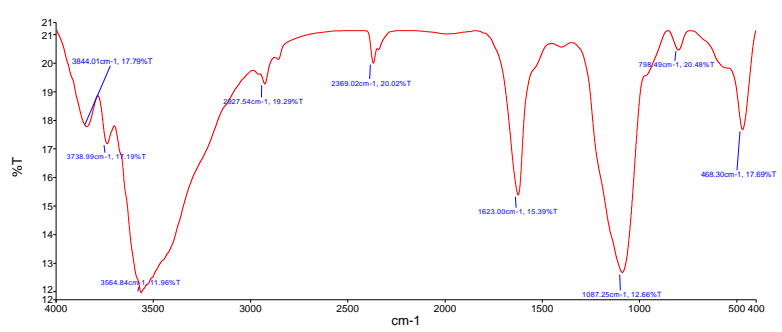

(c)

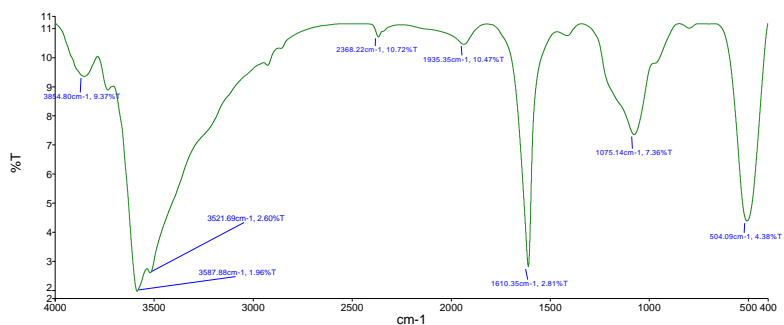

(b)

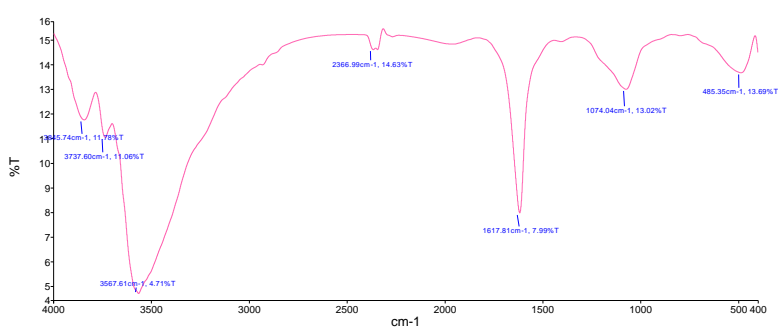

(d)

Gambar 2. Hasil Uji FTIR pada : a. Sampel Stasiun 1; b. Sampel Stasiun 2; c. Sampel Stasiun 3; d. Sampel Stasiun 4 
Tabel 2. Interpretasi Hasil FTIR

\begin{tabular}{cccc}
\hline No & $\begin{array}{c}\text { Nilai Puncak Panjang } \\
\text { Gelombang }\left(\mathrm{cm}^{-1}\right)\end{array}$ & $\begin{array}{c}\text { Interpretasi Nilai Puncak } \\
\text { Panjang Gelombang }\end{array}$ & Pustaka \\
\hline 1 & $3570-3200$ & OH stretch & \\
2 & $3510-3460$ & NH stretch & \\
3 & $2935-2915$ & CH stretch & \\
4 & $1650-1590$ & NH bend & Coates $(2000)$ \\
5 & $1350-1000$ & C - C stretch & \\
6 & $1225-950$ & Aromatic CH in plane bend & \\
7 & $1150-1000$ & C-F & \\
8 & $1090-1020$ & Aromatic CH out of plane bend & \\
9 & $900-670$ & C-Cl & \\
10 & $800-700$ & S-S stretch & \\
11 & $500-430$ & &
\end{tabular}

\section{KESIMPULAN}

Pada muara Sungai Kendal, didapatkannya 4 jenis bentuk mikroplastik yaitu fragment, fiber, film, dan foam, sedangkan jens polimer mikroplastik teridentifikasi adanya 3 jenis yaitu polyethylene, polypropylene, dan polyamide. Terdapatnya mikroplastik pada muara Sungai Kendal dapat dikarenakan adanya masukkan sampah dari darat seperti pada Kecamatan Patukangan - Pegulon yang merupakan kawasan industri dan padata penduduk atau adanya kegiatan manusia pada daerah muara seperti penangkapan ikan ataupun kegiatan sehari - hari yang dilakukan oleh masyarakat Desa Bandengan

\section{DAFTAR PUSTAKA}

Ayuningtyas, W.C., Yona D., Julinda, S.H. \& Iranawati, F. Kelimpahan Mikroplastik Pada Perairan Di Banyuurip, Gresik, Jawa Timur. Journal of Fisheries and Marine Research., 3(1):41-45.

Dinas Pusdataru. Daftar Daerah Aliran Sungai (DAS) Per Wilayah Sungai (WS) Di Jawa Tengah Sesuai Peraturan Presiden RI No 12 Tahun 2012 Ttg Penetapan Wilayah Sungai. 5 Januari 2017 [diakses 1 Januari 2020].

Coates, J. 2000. Interpretation of Infrare Spectra, A Practical Approach. John Wiley \& Sons Ltd., Chichester, 10881-10882.

Iwasaki, S., Isobe, A., Kako,, S. Uchida, K., \& Tokai, T. 2017. Fate of Microplastics and Mesoplastics Carried by Surface Currents and Wind Waves: A Numerical Model Approach in The Sea of Japan. Marine Polltion Bulletin, 121:85-96.

Jiang, C., Yin, L., Wen, X., Du, C., Wu, L., Long, Y., Liu, Y., Ma, Y., Yin, Q., Zhou, Z. \& Pan, H. 2018. Microplastics in Sediment and Surface Water of West Dongting Lake and South Dongting Lake: Abundace, Source and Composition. International Journal of Environmental Research and Public Health., 15:1-15.

Lippiat, S., Opfer, S. \& Arthur, C. 2013. Marine Debris Monitoring and Assessment: Recommendations for Monitoring Debris Trends in the Marine Environment. NOAA Technical Memorandum NOS-OR\&R-46. Silver Spring, $56 \mathrm{p}$.

Lusher, A.L., Welden, N.A., Sobral, P. \& Cole, M 2017. Sampling Isolation and Identifying Microplastics Ingested by Fish and Invertebrates. Analytical Methods., 9:1346-1360

Maulina, W. 2016. Kajian Membran Komposit Nilon-Arang Melalui Karakterisasi FTIR dan SEM. Jurnal Pendidikan Fisika dan Keilmuan, 2(1):56-60. 
Pawar, P.R., Shirgaonkar, S.S. \& Patil, R.B. 2016. Plastic Marine Debris: Sources, Distribution and Impacts on Coastal and Ocean Biodiversity. Pencil Publication of Biological Sciences, 3(1):4054.

Pemerintah Kabupaten Kendal. 2012. Rencana Pembangunan Jangka Menengah Daerah (RPJMD) Kabupaten Kendal Tahun 2010-2015. Lampiran Peraturan Daerah Kabupaten Kendal Nomor 5 Tahun 2011.

Poedjiastoeti, H. \& Karmila, M. 2008. Karakteristik Kondisi Sanitasi Lingkungan di Kawasan Pemukiman Nelayan Bandengan Kabupaten Kendal. 1-15.

Rasyid, B.F., Kurniani, D., Italiano, J. \& Sugiyanto. 2017. Kajian Sistem Drainase PatukanganPegulon Kabupaten Kendal. Jurnal Karya Teknik Sipil., 6(2):276-285.

Suhenda, E. 2008. Teknik Pengambilan, Identifikasi, dan Penghitungan Kelimpahan Plankton di Perairan Teluk Jakarta. Buletin Teknik Litkayasa Sumber Daya, 7(2):51-55.

Syakti, A.D. 2017. Microplastics Monitoring in Marine Environment. Omni-Akuatik, 11(2):1-6.

Solomon, O.O. \& Palanisami, T. 2016. Microplastics in the Marine Environment: Current Status, Assessment Methodologies, Impacts and Solutions. Journal of Pollution Effects \& Control., 4(2):1-13.

Thiele, C.J., Hudson, M.D. \& Russell, A.E. 2019. Evaluation of existing methods to extract microplastics from bivalve tissue: Adapted $\mathrm{KOH}$ digestion protocol improves filtration at singledigit pore size. Marine Pollution Bulletin,142:384-393.

United Nations Environment Programme [UNEP]. 2011. UNEP Year Book 2011: Emerging Issues in Our Global Environment. UNEP Division of Early Warning and Assessment, Nairobi, 79p.

Viršek, M.K., Palatinus, A., Koren., S., Peterlin, M., Horvat, P. \& Kržan, A. 2016. Protocol for Microplastics Sampling on the Sea Surface and Sample Analysis. Journal of Visualized Experiments., 118:1-9.

Wang, Z., Taylor, S.E., Sharma, P. \& Flury, M. 2018. Poor Extraction Efficiencies of Polystyrene Nano- and Microplastics From Biosolids and Soil. PLoS ONE., 13(11): e0208009.

Yin, L., Jiang, C., Wen, X., Du, C., Zhong, W., Feng, Z., Long, Y., \& Ma, Y. 2019. Microplastic Pollution in Surface Water of Urban Lakes in Changsha, China. International Journal of Environmental Research and Public Health, 16(1650):1-10. 